\title{
summary
}

\section{Personal oral hygiene is essential to dental health but professional treatment and frequent maintenance are not universally necessary}

Brothwell DJ, Jutai DKG, Hawkins RJ. An update of mechanical oral hygiene practices: evidence-based recommendations for disease prevention. Can Dental J 1998; 64:295-306

Objective To update a review of dental plaque control measures and oral hygiene practices presented at the National Institute of Dental Research Conference in 1986.

Design Medline 1984-1995, using the search-terms periodontal disease, dental caries, oral hygiene, toothbrushing, flossing, interdental, irrigation, scaling, prophylaxis and root planing.

Study selection Only human studies assessing mechanical oralhygiene interventions using disease outcome measurements were included. Chemical or pharmaceutical interventions were excluded. Selected studies were rated using levels of evidence developed by the Canadian Task Force on Periodic Health Examination.

Results Using the levels of evidence shown below, a series of graded recommendations was made covering 23 areas (see pages XX).

Conclusion Although personal oral hygiene is essential to dental health, professional treatment and frequent maintenance are not universally necessary. The benefits and risks of all mechanical oral hygiene practices must be carefully considered.

\begin{tabular}{|c|c|}
\hline Level & Evidence \\
\hline I & Evidence from at least one properly randomised controlled trial \\
\hline II & $\begin{array}{l}\text { Evidence from at least one well-designed controlled trial without } \\
\text { randomisation, from cohort or case-control analytic studies, } \\
\text { preferably from more than one centre, from multiple time series, } \\
\text { or from dramatic results in uncontrolled experiments }\end{array}$ \\
\hline III & $\begin{array}{l}\text { Evidence from opinions of respected authorities on the basis of } \\
\text { clinical experience, descriptive studies, or reports of expert } \\
\text { committees }\end{array}$ \\
\hline Level & Recommendation \\
\hline A & Good evidence to support a recommendation for use \\
\hline B & Moderate evidence to support a recommendation for use \\
\hline C & Recommendation for, or against, use based on poor evidence \\
\hline $\mathrm{D}$ & Moderate evidence to support a recommendation against use \\
\hline $\mathrm{E}$ & Good evidence to support a recommendation against use \\
\hline NR & No evidence available to make a recommendation \\
\hline
\end{tabular}

Address for reprints: Dr D Brothwell, Department of Community Dentistry, Faculty of Dentistry, University of Toronto, 124 Edward Street, Toronto, Ontario M5G 1G6, Canada.

\section{Commentary}

This paper reviews the literature on mechanical oral hygiene practices. It provides extremely useful recommendations supported by evidence. Furthermore, it makes clear what level of evidence is available for each of the recommendations. It is a great shame that no data are given regarding the internal and external validity of the papers reviewed. This is disappointing, as such an analysis is reported to have been carried out. Despite the very obvious worth and usefulness of this review paper, this is an important omission. Presumably, some of the studies included had questionable internal and/or external validity and yet, for each type of intervention, the authors base the recommendation simply upon whether or not a randomised controlled trial (RCT), analysis of some other kind, or no analysis had been undertaken. It is essential that people interested in the evidence-base recognise that a badlydesigned RCT may lead to as many errors of interpretation as well-run studies that employ less respected study designs. If the most valid studies showed no effect from a given intervention whereas less valid studies (those with poor design or small numbers) showed a positive effect, the conclusion must be drawn that no real effect existed. Similarly, if studies that were both externally and internally valid showed no effect whereas those with lower validity did show an effect, the conclusion should be drawn that the intervention effect was real but small (ie, not revealed by studies with, for example, low power). The monitoring of validity is thus essential.

The authors undoubtedly took such effects into consideration when making their recommendations and this paper is an important contribution to the evidence base. Detailed exposure of their methodology, however, would allow others to underpin their practice and their advice with the most robust evidence available.

Liz Kay
University Dental Hospital,
Manchester, UK


Table 1. Summary of recommendations: personal oral hygiene measures

\begin{tabular}{|c|c|c|c|}
\hline Practice & Effectiveness & $\begin{array}{l}\text { Level of } \\
\text { evidence }\end{array}$ & Recommendation \\
\hline Toothbrushing & $\begin{array}{l}\text { Twice-daily brushing with fluoridated tooth- } \\
\text { paste prevents caries and controls gingivitis }\end{array}$ & I & $\begin{array}{l}\text { Good evidence to recommend brushing twice daily with fluoride } \\
\text { dentifrice for caries prevention and control of gingivitis }(A)^{*}\end{array}$ \\
\hline Nylon-bristled toothbrushes & $\begin{array}{l}\text { Any soft-bristled toothbrush can be used in the } \\
\text { control of gingivitis }\end{array}$ & I & $\begin{array}{l}\text { Moderate evidence to recommend using any commercially } \\
\text { available soft-bristled toothbrush }(B)\end{array}$ \\
\hline Foam toothbrushes & $\begin{array}{l}\text { Less effective than conventional toothbrushes } \\
\text { in control of gingivitis }\end{array}$ & I & $\begin{array}{l}\text { Moderate evidence not to recommend using foam brushes for } \\
\text { control of gingivitis (D) }\end{array}$ \\
\hline $\begin{array}{l}\text { Oscillating/rotating or } \\
\text { counter-rotating electrically- }\end{array}$ & $\begin{array}{l}\text { More effective than manual toothbrushes in } \\
\text { controlling gingivitis }\end{array}$ & 1 & $\begin{array}{l}\text { Good evidence to recommend use of oscillating/rotating or } \\
\text { counter rotational electric toothbrushes for control of gingivitis }(A)\end{array}$ \\
\hline powered toothbrushes & & I & $\begin{array}{l}\text { Recommended for limited dexterity, non-compliant, and fixed } \\
\text { orthodontic appliance patients }(A)\end{array}$ \\
\hline $\begin{array}{l}\text { Rotating, vibrating or sonic- } \\
\text { action electrically-powered } \\
\text { toothbrushes }\end{array}$ & $\begin{array}{l}\text { Not more effective than manual toothbrushing } \\
\text { in controlling gingivitis }\end{array}$ & I & $\begin{array}{l}\text { Moderate evidence to not recommend use of rotary, vibrating } \\
\text { or sonic action electric toothbrushes for most adults (D) }\end{array}$ \\
\hline \multirow[t]{3}{*}{ Dental floss } & $\begin{array}{l}\text { More effective than toothbrushing alone in } \\
\text { controlling gingivitis in adults }\end{array}$ & 1 & $\begin{array}{l}\text { Good evidence to recommend flossing as an adjunct to } \\
\text { toothbrushing for control of gingivitis in adults }(A)\end{array}$ \\
\hline & Not effective in preventing gingivitis in children & I & $\begin{array}{l}\text { Moderate evidence not to recommend flossing to control } \\
\text { gingivitis in children (D) }\end{array}$ \\
\hline & $\begin{array}{l}\text { More effective than toothbrushing alone in } \\
\text { controlling periodontitis }\end{array}$ & II & $\begin{array}{l}\text { Moderate evidence to recommend one method of interdental } \\
\text { hygiene for control of periodontitis }(B)\end{array}$ \\
\hline Wooden interdental cleaner & $\begin{array}{l}\text { More effective than toothbrushing alone in } \\
\text { controlling gingivitis in adults }\end{array}$ & II & $\begin{array}{l}\text { Moderate evidence to recommend use of wooden interdental } \\
\text { cleaners for control of gingivitis in adults }(B)\end{array}$ \\
\hline Interdental brush & $\begin{array}{l}\text { Not more effective than toothbrushing alone in } \\
\text { reducing gingivitis }\end{array}$ & II & $\begin{array}{l}\text { Moderate evidence not to recommend use of interdental } \\
\text { brushes (D) }\end{array}$ \\
\hline Unituft or end-tuft brush & $\begin{array}{l}\text { Effective adjunct to toothbrushing in controlling } \\
\text { gingivitis in adults }\end{array}$ & I & $\begin{array}{l}\text { Moderate evidence to recommend unituft or end-tuft brushes } \\
\text { for control of gingivitis, for adults not performing interdental } \\
\text { hygiene (B) }\end{array}$ \\
\hline Gingival massage & $\begin{array}{l}\text { Not more effective in controlling gingivitis } \\
\text { compared with toothbrushing alone }\end{array}$ & II & $\begin{array}{l}\text { Moderate evidence not to recommend the use of rubber-tip } \\
\text { stimulation as a supplemental method of controlling gingivitis (D) }\end{array}$ \\
\hline Supragingival irrigation & $\begin{array}{l}\text { Effective in controlling gingivitis in adults with } \\
\text { inadequate oral hygiene or patients with } \\
\text { orthodontic appliances }\end{array}$ & I & $\begin{array}{l}\text { Good evidence to recommend supragingival irrigation for } \\
\text { control of gingivitis for adults with inadequate oral hygiene or } \\
\text { patients with orthodontic appliances }(A)\end{array}$ \\
\hline Subgingival irrigation & Not evaluated as an adjunct to toothbrushing & - & No recommendation \\
\hline Tongue brushing or scraping & Not effective in controlling gingivitis & 1 & $\begin{array}{l}\text { Moderate evidence to recommend against tongue brushing for } \\
\text { controlling gingivitis (D) }\end{array}$ \\
\hline
\end{tabular}

${ }^{*}$ Caries reduction may be largely due to the effect of fluoride.

Table 2. Summary of recommendations: professional oral hygiene measures

\begin{tabular}{|c|c|c|}
\hline Practice & Effectiveness & Recommendation \\
\hline
\end{tabular}

Scaling Scaling may be as effective as surgery in arresting periodontal destruction in disease active sites, when followed by long-term maintenance therapy Supragingival scaling effective in maintaining periodontal health, when combined with adequate personal oral hygiene

Subgingival scaling of shallow pockets can cause loss of periodontal attachment

Subgingival scaling may not be necessary in maintenance therapy, if personal oral hygiene is adequate

Scaling frequency Patients with histories of moderate/severe periodontitis: scaling of disease active sites, at 3- to 4-month intervals, is effective in maintaining periodontal health For most patients: regular dental visits are associated with less periodontal attachment loss; no evidence that 6-month recall is optimal frequency

Ultrasonic devices Compared with hand instruments, equally effective in treatment of single-rooted teeth

Root planing

No evidence regarding additional benefits of root planning in periodontal therapy

Polishing Polishing, prior to topical fluoride application (TFA), is not necessary for maximum caries prevention

Rubber cup and paste Not effective in controlling gingivitis

Air polishing Not evaluated

Removal of overhangs Restoration overhangs are associated with deeper periodontal pockets Method of overhang removal has not been evaluated Supragingival irrigation Controls gingivitis when used at frequent intervals; intervals with saline/water Subgingival irrigation between procedures unsuitable for professional practice When combined with scaling, may control periodontal professional practice evidence

I Good evidence to recommend scaling for initial therapy in patients with active periodontitis, when combined with maintenance therapy $(A)$

II Moderate evidence to recommend supragingival scaling of disease active sites, for maintenance therapy (B)

I Good evidence to recommend against subgingival scaling in sites with no signs of disease (E)

II Moderate evidence to recommend against subgingival scaling for maintenance therapy, if personal oral hygiene adequate (D)

II Moderate evidence to recommend maintenance therapy every 3 to 4 months for patients with histories of moderate or severe periodontitis (B)

I Moderate evidence to recommend the scaling of disease active sites at intervals of $>6$ months based on patient need (B)

I Moderate evidence to recommend the use of ultrasonic devices in periodontal therapy of single-rooted teeth (B) No recommendation

II Good evidence to recommend against polishing prior to TFA for caries prevention (E)

I Good evidence to recommend against polishing for control of gingivitis (E)

No recommendation

II Moderate evidence to recommend the removal of overhanging margins for periodontal therapy (B)

No recommendation

III Not recommended for use in periodontal therapy (C)

I Not recommended for use in periodontal therapy (C) 